\title{
An Exploration of Body Dissatisfaction and Perceptions of Black and White Girls Enrolled in an Intervention for Overweight Children
}

\author{
N. R. Kelly ${ }^{\mathrm{a}}$, C. M. Bulik ${ }^{\mathrm{b}}$, and S. E. Mazzeo ${ }^{\mathrm{c}}$ \\ N. R. Kelly: nrkelly@vcu.edu; C. M. Bulik: cbulik@med.unc.edu; S. E. Mazzeo: semazzeo@vcu.edu \\ a Department of Psychology, Virginia Commonwealth University, P.O. Box 842018, Richmond, \\ VA, 23284 USA \\ b Departments of Psychiatry and Nutrition, University of North Carolina at Chapel Hill, CB 7160, \\ Chapel Hill, NC 27599, USA \\ c Department of Psychology and Pediatrics, Virginia Commonwealth University, P.O. Box \\ 842018, Richmond, VA, 23284, USA
}

\begin{abstract}
Silhouette measures are one approach to assessing body dissatisfaction in children, although little is known about their use among racially diverse, overweight girls seeking weight-loss treatment. This study assessed racial differences in body dissatisfaction and body size perceptions of 58 girls (ages 6-11, 66\% Black, 34\% White) participating in a randomized trial for pediatric overweight. Body dissatisfaction did not differ between races; $99 \%$ of girls reported an ideal figure smaller than their current one. Black girls selected a larger silhouette to represent their ideal body size, and most girls in both racial groups underestimated their actual size. Outcomes strengthen the argument that, despite an overall preference for a larger body size, obesity might mitigate cultural factors that protect Black girls from body dissatisfaction. Additional research is needed to enhance understanding of children's body size perceptions and dissatisfaction to inform assessment and treatment of pediatric obesity and associated disordered eating symptoms.
\end{abstract}

\section{Keywords}

overweight; obesity; child; Black; body dissatisfaction; silhouette measure

Over a third of children between the ages of 6 and 11 are overweight (body mass index $[\mathrm{BMI}]$ for age $\geq 85^{\text {th }}$ percentile) or obese (BMI $\geq 95^{\text {th }}$ percentile; Ogden, Carroll, Curtin, Lamb, \& Flegal, 2010). Pediatric overweight and obesity are not only associated with significant physical health problems (Kiess et al., 2001), but also are risk factors for body dissatisfaction and other eating disorder pathology (Fairburn et al., 1998; Fairburn, Welch, Doll, Davies, \& O'Connor, 1997; Shunk \& Birch, 2004; Stice \& Shaw, 2002). For example,

\footnotetext{
(C) 2011 Elsevier Ltd. All rights reserved.

Correspondence to: Suzanne Mazzeo, Ph.D. 806 W. Franklin St. P.O. Box 842018, Richmond, VA 23284-2018, USA, 804.239.3169 (fax); 804.827.9211 (phone), semazzeo@vcu.edu.

Conflict of Interest: All authors declare that they have no conflicts of interest.

Publisher's Disclaimer: This is a PDF file of an unedited manuscript that has been accepted for publication. As a service to our customers we are providing this early version of the manuscript. The manuscript will undergo copyediting, typesetting, and review of the resulting proof before it is published in its final citable form. Please note that during the production process errors may be discovered which could affect the content, and all legal disclaimers that apply to the journal pertain.
} 
girls who are overweight at age five are significantly more likely to report eating pathology at age nine, including weight concern, disinhibited eating, and dietary restraint (Shunk \& Birch, 2004). Further, girls as young as five report body dissatisfaction (Lowes \& Tiggemann, 2003), which is an identified risk factor for eating disorders (Stice \& Shaw, 2002). Thus, considering the pervasiveness of obesity and body dissatisfaction among children, a large percentage of girls in the United States (U.S.) might be at risk for developing disordered eating pathology.

Pediatric obesity is more common among Black children in the U.S. compared with their White peers (Ogden et al., 2010). Given the noted associations between BMI and body dissatisfaction (Stice \& Shaw, 2002), one might expect overweight Black girls to report greater dissatisfaction with their body size. Yet, historically, this has not been the case. Rather, overweight Black girls typically endorse a larger ideal body size and greater body satisfaction than White girls (e.g., Davis, Sbrocco, \& Williams, 2009), findings attributed to cultural variations in body ideals and greater tolerance of weight diversity (Skelton, Busey, $\&$ Havens, 2006). However, overweight Black girls seeking weight-loss treatment report levels of psychological distress (including low quality of life and self-esteem) similar to those of their White peers (Schwimmer, Burwinkle, \& Varni, 2003; Stern et al., 2007). These findings, although somewhat inconsistent across studies (e.g., Fallon et al., 2005), have led some to propose that a general cultural preference for a larger body size does not buffer Black girls at the extremes of overweight and obesity against negative psychological outcomes (Stern et al., 2007). However, less is known about body dissatisfaction among Black girls seeking weight-loss treatment.

Silhouette measures are one method used to assess body dissatisfaction and are appropriate for children as young as five (Collins, 1991). Although commonly used in pediatric samples to assess body dissatisfaction (Davis et al., 2009; Rasmussen, Eriksson, \& Nordquist, 2007; Rolland, Farnill, \& Griffiths, 1997; Truby \& Paxton, 2008; Wallander et al., 2009; Welch, Gross, Bronner, Dewberry-Moore, \& Paige, 2004; Young-Hyman, Schlundt, HermanWenderoth, \& Bozylinski, 2003; Young-Hyman et al., 2006), significantly less data are available regarding correlates of these measures in overweight children seeking weight-loss treatment. One of the few available studies suggested that overweight children reported high levels of body dissatisfaction (Zeller, Ingerski, Wilson, \& Modi, 2010). However, the measure used in this study included a restricted range of three silhouettes (representing underweight, average weight and obese body sizes). A measure with greater range, such as that used in the current study, might be better able to identify possible links between body size perceptions and ideals.

Another limitation of previous research in this area is that few investigations have included substantial numbers of Black girls, despite the high prevalence of obesity in this group (Ogden et al., 2010). The study by Zeller and colleagues (2010) did include Black girls; however, it also included boys, and most analyses were conducted with both genders combined. The current study focuses on girls exclusively, as research has identified substantial gender differences in body dissatisfaction, perceptions, and ideals (Rasmussen et al., 2007; Rolland et al., 1997; Truby \& Paxton, 2008; Welch et al., 2004; Young-Hyman et al., 2006). Moreover, the current study extends prior research, which has primarily been conducted with community-based adolescent populations (e.g., Rasmussen et al., 2007; Wallander et al., 2009), to a younger, clinical sample. A significant body of work has suggested that children and adolescents seeking weight-loss treatment differ in several important ways from overweight youth included in community samples (Eddy et al., 2007; Schwimmer et al., 2003). In particular, relative to their peers in the community, treatmentseeking children and adolescents report higher levels of disordered eating and general psychopathology (e.g., mood and anxiety disorders) and poorer quality of life (Eddy et al., 
2007; Schwimmer et al., 2003). Thus, results from non-clinical samples are unlikely to generalize to treatment-seeking children, and additional research is needed with this particularly vulnerable group.

Another reason it is important to investigate overweight children's body size perceptions and ideals is that these variables could reduce the effectiveness of pediatric weight management interventions (Wang, Liang, \& Chen, 2009). Overweight children and adolescents are more likely to under-report their weight relative to their normal weight peers (e.g., Elgar \& Stewart, 2008; Jorga, Marinkovic, Kentric, \& Hetherington, 2007; Maximova et al., 2008; Wang et al., 2009; Zeller et al., 2010). Youth who are overweight, but perceive their body size as normal might have limited motivation to change their health behaviors. This hypothesis is supported by data suggesting that Black adolescents who perceived themselves as overweight were more likely to try and lose weight (Wang et al., 2009). On the other hand, unrealistic weight loss goals (i.e., large discrepancies between actual and preferred body sizes) and body dissatisfaction are associated with poorer weight loss outcomes and greater attrition among women enrolled in obesity treatment (Dalle Grave et al., 2005; Teixeira et al., 2004). Despite these potential clinical implications, very little research has explored these variables (e.g., body size perceptions and preferences) among overweight children seeking treatment. Exploration of the influence of children's race is also lacking.

Thus, the current study's aims were: (a) to examine differences in BMI percentile, body dissatisfaction, body size ideals, and body size perceptions between overweight White and Black girls enrolled in a pediatric obesity intervention, and (b) to explicate the associations among these variables. It was hypothesized that body dissatisfaction, assessed using a silhouette measure, would not differ between Black and White participants, but that Black girls would endorse a larger ideal body size. It was further hypothesized that BMI percentile and body dissatisfaction would be significantly and positively correlated. All other analyses were exploratory considering the relative dearth of research including treatment-seeking, racially diverse pediatric samples.

\section{Method}

\section{Participants}

This study assessed racial differences in BMI percentile, body size perceptions and ideals, and body dissatisfaction among girls participating in an intervention for overweight children (NOURISH-Nurturing Our Understanding of Role modeling to Improve Support and Health). The methods used in this clinical trial are described in detail elsewhere (Mazzeo et al., manuscript under review). To qualify for participation, parents/caregivers had to be at least 18 years of age and have a child between the ages of 6 and 11 with a BMI $\geq$ the $85^{\text {th }}$ percentile for their age and sex according to the CDC Growth Charts (Kuczamarski, Ogden, Guo, Grummer-Strawn, \& Flegal, 2002). This child also had to reside primarily in the participating caregiver's home. Multiple children from the same family were permitted to participate if they met all eligibility requirements. Briefly, families were recruited for NOURISH from within a 30-mile radius of Richmond, Virginia. Unpaid advertisements (i.e., fliers) were used to recruit participants from local elementary schools, community recreation centers, and pediatric health care professionals. A brief phone screen was used to determine eligibility. Families who completed baseline measures were compensated with a $\$ 25.00$ gift card to a major retailer.

A total of 84 families enrolled in NOURISH and completed baseline assessments, including 91 children $(M$ age $=8.59, S D=1.50 ; 63 \%$ female $)$. The majority of participating families identified as Black (61.5\%), followed by White (36.5\%), and Hispanic/Latino/a (less than 
$1 \%)$. Only Black $(n=36)$ and White $(n=22)$ girls were included in the current analyses. Their mean BMI percentile was $97.58(S D=3.13)$.

\section{Measures}

Figure rating scale-Body dissatisfaction, body size perceptions, and body size preferences were assessed using silhouettes (Pulvers et al., 2004; see Figure 1). This measure includes nine rank ordered figures which incrementally increase in size from underweight to overweight. Respondents were instructed to select their current (i.e., body size perception) and ideal silhouettes (i.e., body size preference). Body dissatisfaction was calculated by ascertaining the absolute difference between participants' ideal and current silhouettes. Larger discrepancies were indicative of greater body dissatisfaction. This instrument was designed to appear ethnically neutral, thereby maximizing its suitability for participants from varied ethnic backgrounds. It has been used with Black and White women in community and clinical settings, and demonstrated excellent estimated inter-rater reliability, as well as good content, convergent, and concurrent validity (Pulvers et al., 2004, 2008). This measure has also been used with Black and White adolescents enrolled in a weight management intervention, and demonstrated good convergent and content validity. Specifically, it was significantly correlated with both a well-validated self-report measure of body image (the Multidimensional Body-Self Relations Questionnaire, Cash, 2000), and with participants' BMI (Porter, 2008).

Anthropometric measures-Height was measured by trained staff to the nearest $1 / 4$ inch using a stadiometer. Weight was measured to the nearest $1 / 4 \mathrm{lb}$. using a medical balance beam scale. Participants were asked to remove heavy clothing and their shoes prior to undergoing measurements. These data were collected in a private room and used to calculate BMI percentile (Kuczamarski et al., 2002).

Demographics questionnaire-This questionnaire asked participants' parents/ caregivers to provide their children's age, race, and gender.

Procedure

The protocol for this study was approved by the governing Institutional Review Board. All assessments occurred at a community-based clinic. As part of their baseline evaluation, children were interviewed individually by a doctoral student in psychology and were presented with the silhouette measure described previously. Height and weight were gathered in a private room on the same day.

\section{Statistical Analyses}

Descriptive statistics were conducted and independent samples $t$-tests were used to explore differences in BMI percentiles, body size perceptions, ideals, and dissatisfaction between White and Black girls. For exploratory purposes, mean BMI percentile values were calculated for each silhouette selected, both for the total sample and for each racial group. Pearson's correlations were used to examine the relation between BMI percentile and body size perceptions, ideals, and dissatisfaction. All $p$ values are two-sided, with $p<.05$ considered statistically significant.

\section{Results}

\section{Body Size Perceptions, Ideals, and Dissatisfaction}

Body dissatisfaction did not differ between White $(M=1.93, S D=0.87)$ and Black girls $(M$ $=2.23, S D=1.16), t(55)=-1.19, p=.237$. Moreover, only one girl from the entire sample 
was satisfied with her body (i.e., selected the same silhouette as her perceived and ideal one). All other participants selected a smaller ideal silhouette than their current one. In addition, compared to White girls $(M=1.90, S D=1.00)$, Black girls $(M=2.53, S D=0.97)$ endorsed a larger ideal silhouette, $t(55)=-2.32, p=.024$. Indeed, $47.6 \%$ of White girls preferred the first silhouette, $19 \%$ preferred the second, $28.6 \%$ preferred the third, and $4.8 \%$ preferred the fourth. In contrast, $13.9 \%$ of Black girls preferred the first silhouette, $36.1 \%$ preferred the second, $36.1 \%$ preferred the third, $11.1 \%$ preferred the fourth, and $2.8 \%$ preferred the fifth. Black girls $(M=4.81, S D=1.24)$ also selected a larger silhouette to represent their current body size, $t(55)=-2.99, p=.004$, compared to White girls $(M=$ $3.83, S D=1.09)$. Specifically, the average silhouette selection for Black girls was one larger than that of White girls. Consistent with this selection, the average BMI for Black girls was higher $\left(98.1^{\text {st }}\right.$ percentile vs. $96.8^{\text {th }}$ percentile). However, this difference was not statistically significant, $t(56)=-1.50, p=.139$.

Pearson's correlations for the entire sample indicated that BMI percentile was positively associated with body dissatisfaction $(r=.44, p<.001)$. Furthermore, girls with higher body dissatisfaction selected a larger silhouette to represent their current body size $(r=.63, p<$. 001). Finally, as body dissatisfaction increased, the size of the ideal silhouette decreased ( $r=$ $-.26, p=.048)$.

\section{BMI and Silhouette Selection}

Mean BMI percentiles for the total sample, Black girls, and Whites girls were calculated for each silhouette endorsed on item one of the figure rating scale (i.e., current body size perceptions). As Table 1 indicates, most girls underestimated their body size. The most frequently selected silhouette was in the middle range of those presented although the mean BMI for the sample was $97.58 \%$. Only two participants selected silhouettes seven, eight, or nine to represent their current body size.

\section{Discussion}

This study is the first to suggest that both Black and White girls seeking weight-loss intervention report similarly high levels of body dissatisfaction. However, despite endorsing comparable levels of body dissatisfaction, Black girls indicated a preference for a larger body size than their White peers, consistent with previous research (e.g., Davis et al., 2009; Welch et al., 2004). Current outcomes thus strengthen the emerging argument that, despite an overall preference for a larger body size, this cultural tolerance for size diversity might not extend to the higher end of the BMI spectrum, especially among individuals seeking weight-loss treatment (Eddy et al., 2007; Schwimmer et al., 2003; Stern et al., 2007). It is also noteworthy that, while Black girls in this study endorsed a larger body size preference than their White peers, their average ideal silhouette was significantly smaller than that reported by Black youth in the community (e.g., Jorga et al., 2007; Rolland et al., 1997; Thompson, Corwin, \& Sargent, 1997). Thus, compared with their community-based peers (Atlas, Smith, Hohlstein, McCarthy, \& Kroll, 2002; Shaw, Ramirez, Trost, Randall, \& Stice, 2004), Black girls enrolled in this pediatric overweight intervention appear to endorse a greater desire for thinness. This finding could have significant clinical implications for racially diverse girls enrolled in weight-loss interventions given the noted association between drive for thinness and body dissatisfaction (see Sands, 1999 for a review).

In addition, as all children in this study were overweight and most were obese, there were large discrepancies between participants' current BMI percentiles and their ideal silhouettes. Specifically, approximately half of White girls endorsed a desire to look like the first silhouette, a body size generally considered underweight (Zeller et al., 2010). This body size is not only unrealistic for this very overweight sample, but is also an unhealthy goal for 
virtually any child. Previous studies have found positive relations among weight loss goals, body dissatisfaction, and treatment attrition for adult women (Dalle Grave et al., 2005; Teixeira et al., 2004; Wang et al., 2009). Additionally, body dissatisfaction was associated with inappropriate weight goals among adolescents from a population-based sample (Roy \& Gauvin, 2009). These previous findings, in combination with those of the current study, suggest that future research should explore overweight children's expectations regarding weight loss, and their potential influence on similar programmatic and eating and weightrelated outcomes.

Results from this study also highlight the pervasiveness of body dissatisfaction among overweight, racially diverse, treatment-seeking girls. As hypothesized, participants with higher BMI percentiles endorsed greater dissatisfaction. Moreover, $99 \%$ of girls in this study preferred a smaller body size than their current one. This is consistent with Zeller and colleagues' (2010) recent investigation of body dissatisfaction among children enrolled in a weight management trial. However, in community-based studies, between $52 \%$ and $63 \%$ of overweight youth preferred a smaller body (e.g., Truby \& Paxton, 2008; Wang et al., 2009). Discrepancies in reported body dissatisfaction across studies might be attributable to the treatment-seeking status of the current sample. Other variables not evaluated in this study might also account for the apparent differences in body dissatisfaction among community and clinical samples, including severity of obesity or parents' eating- and weight-related behaviors (Neumark-Sztainer et al., 2010). Future research should explore the potential moderating properties of these and similar variables. Nonetheless, the fact that all but one overweight participant endorsed dissatisfaction with her current body size is concerning because both body dissatisfaction and elevated BMI mass are risk factors for eating disorders (Stice \& Shaw, 2002).

Outcomes from this study were also consistent with previous research suggesting that overweight girls underestimate their body size (e.g., Elgar \& Stewart, 2008; Jorga et al., 2007; Maximova et al., 2008; Wang et al., 2009; Zeller et al., 2010). For example, Maximova and colleagues (2008) found that $71.4 \%$ of overweight children and adolescents underestimated their body size compared to $30 \%$ of their non-overweight peers. These body size misperceptions could be related to BMI trends in the United States. The prevalence of overweight or obesity in youth is on the rise, and this is particularly true for Black children (Ogden et al., 2010). Given that the majority of this sample was Black, it might be that the body size of the girls in this study is relatively normative within their peer group. Maximova et al. found that weight misperceptions were greater among students whose classmates and parents were heavier. Thus, exposure to larger individuals might increase the likelihood that children underestimate their size. These body size misperceptions could prove problematic if they deter overweight Black children (and their families) from initiating healthy changes.

Although this study provides important directions for future research and clinical intervention, several limitations should be noted. First, this was an exploratory investigation, and between-group sample sizes were relatively small. Nonetheless, this study's outcomes were consistent with its hypotheses. Moreover, a larger clinical trial of NOURISH is currently underway, thereby providing an opportunity to re-evaluate these constructs with a larger sample. A second limitation is that the figure rating scale used in this study has not previously been used with children. However, this limitation is balanced by its validity within racially diverse samples (Porter, 2008; Pulvers et al., 2004, 2008).

Moreover, the sample was exclusively comprised of overweight girls who agreed to participate in a pediatric obesity intervention. As such, results from this study are not generalizable to non-treatment-seeking children. Similarly, the inclusion of only overweight children restricted range in BMI, which might have attenuated its relations with other 
variables. Future studies should expand these analyses to non-treatment seeking children and boys. In addition, the inclusion of both adolescents and younger children in longitudinal designs would permit the exploration of potential developmental trajectories in BMI and body dissatisfaction (Zeller et al., 2010). Despite these limitations, findings from this exploratory study are meant to inform current practices as they relate to pediatric obesity, and thus are clinically meaningful.

Additional research is needed to explore the mechanisms behind and implications of overweight children's weight loss expectations and body size misperceptions. One of the components of effective behavior change might be recognition (on the part of the parent and child) that their weight exceeds the norm and poses a health risk (Rhee, De Lago, ArscottMills, Mehta, \& Davis, 2005). If exposure to an "obesogenic" environment essentially normalizes the weight of overweight and obese children (Welch et al., 2004), families, and the children themselves, might be less motivated to make healthy behavioral changes. On the other hand, considering the prevalence of body dissatisfaction in this sample and the known association between body dissatisfaction and eating disorders (Stice \& Shaw, 2002), it is important to evaluate our current approach to weight-loss interventions to minimize the onset of disordered eating and other problematic weight-related behaviors and attitudes. It is recommended that researchers and interventionists utilize a family-level approach to the promotion of healthy weight-related changes, consider recruiting persons of all sizes who are interested in enhancing their health behaviors, and incorporate modules to address body dissatisfaction directly. This approach has the advantage of avoiding the potential psychological implications of stigma associated with self or other-identification of a specific child as overweight.

The current study's findings also highlight the need for addressing disordered eating risk factors among overweight girls seeking weight-related treatment. This recommendation is particularly relevant for Black girls, who are generally considered less vulnerable to disordered eating (Becker, Franko, Speck, \& Herzog, 2003; Mulholland \& Mintz, 2001). Researchers and clinicians working with overweight children, particularly in a weight management context, should be aware of how these biases might affect their work. Finally, in consideration of this study's findings, additional research is needed to evaluate the efficacy of integrative prevention and treatment efforts which target both disordered eating and obesity.

\section{Conclusions}

In sum, Black and White overweight girls enrolled in a randomized trial for pediatric overweight experienced comparable levels of body dissatisfaction, despite variations in body size preferences. Moreover, all but one girl desired a body size smaller than her current one, indicating the presence of significant body dissatisfaction. Significant weight misperceptions were also evident. For these reasons, research evaluating the impact of body dissatisfaction, body size ideals, and body size perceptions on pediatric obesity intervention efforts is needed. Greater attention to eating disorder risk factors among racially-diverse, overweight, treatment-seeking children is also recommended.

\section{Acknowledgments}

Role of Funding Sources: Funding for this study was provided by NIH Grant HD056050-01A1 (PI, Mazzeo). NIH had no role in the study design, collection, analysis or interpretation of the data, writing the manuscript, or the decision to submit the paper for publication. 


\section{References}

Atlas JG, Smith GT, Hohlstein LA, McCarthy DM, Kroll LS. Similarities and differences between Caucasian and African American college women on eating and dieting expectancies, bulimic symptoms, dietary restraint, and disinhibition. International Journal of Eating Disorders. 2002; 32:326-334. [PubMed: 12210647]

Becker AE, Franko DL, Speck A, Herzog DB. Ethnicity and differential access to care for eating disorder symptoms. International Journal of Eating Disorders. 2003; 33:205-212. [PubMed: 12616587]

Cash. The multidimensional body-self relations questionnaire users' manual. 2000. Available from www.body-images.com

Collins ME. Body figure perceptions and preferences among preadolescent children. International Journal of Eating Disorders. 1991; 10:199-208.

Dalle Grave R, Calugi S, Molinari E, Petroni ML, Bondi M, Compare A, et al. Group QS. Weight loss expectations in obese patients and treatment attrition: an observational multicenter study. Obesity Research. 2005; 13:1961-1969. [PubMed: 16339128]

Davis DS, Sbrocco T, Williams J. Understanding body image in African American and Caucasian first-graders: a partnership with the YMCA. Progress in Community Health Partnerships: Research, Education and Action. 2009; 3:271.

Eddy KT, Tanofsky-Kraff M, Thompson-Brenner H, Herzog DB, Brown TA, Ludwig DS. Eating disorder pathology amoung overweight treatment-seeking youth: Clinical correlates and crosssectional risk modeling. Behaviour Research and Therapy. 2007; 45:2360-2371. [PubMed: 17509523]

Elgar FJ, Stewart JM. Validity of self-report screening for overweight and obesity. Evidence from the Canadian Community Health Survey. Canadian Journal of Public Health. 2008; 99:423-427.

Fairburn CG, Doll HA, Welch SL, Hay PJ, Davies BA, O’Connor ME. Risk factors for binge eating disorder: A community-based, case-control study. Archives of General Psychiatry. 1998; 55:425432. [PubMed: 9596045]

Fairburn CG, Welch SL, Doll HA, Davies BA, O'Connor ME. Risk factors for bulimia nervosa: A community-based case-control study. Archives of General Psychiatry. 1997; 54:509-517. [PubMed: 9193191]

Fallon EM, Tanofsky-Kraff M, Norman AC, McDuffie JR, Taylor ED, Cohen ML, Yanovski JA. Health-related quality of life in overweight and nonoverweight black and white adolescents. Journal of Pediatrics. 2005; 147:443-450. [PubMed: 16227028]

Jorga J, Marinkovic J, Kentric B, Hetherington M. Alternative methods of nutritional status assessment in adolescents. Collegium Antropologicum. 2007; 31:413-418. [PubMed: 17847917]

Kiess W, Galler A, Reich A, Muller G, Kapellen T, Deutscher J, Kratzsch J. Clinical aspects of obesity in childhood and adolescence. Obesity Review. 2001; 1:29-36.

Kuczamarski R, Ogden C, Guo S, Grummer-Strawn L, Flegal K. 2000 CDC Growth Charts for the United States: Methods and Development. Vital Series and Health Statistics Series. 2002; 11:1190.

Lowes J, Tiggemann M. Body dissatisfaction, dieting awareness and the impact of parental influence in young children. British Journal of Health Psychology. 2003; 8:135-147. [PubMed: 12804329]

Maximova K, McGrath JJ, Barnett T, O’Loughlin J, Paradis G, Lambert M. Do you see what I see? Weight status misperception and exposure to obesity among children and adolescents. International Journal of Obesity. 2008; 32:1008-1115. [PubMed: 18317474]

Mazzeo, S.; Kelly, NR.; Stern, M.; Gow, R.; Serdar, K.; Evans, RK....; Bulik, CM. Nourishing Our Understanding of Role Modeling to Improve Support and Health (NOURISH): Design and Methods. 2011. Manuscript submitted for publication

Mulholland AM, Mintz LB. Prevalence of eating disorders among African American women. Journal of Counseling Psychology. 2001; 48:111-116.

Neumark-Sztainer, D.; Bauer, KW.; Friend, S.; Hannan, PJ.; Story, M.; Berge, JM. Family weight talk and dieting: how much do they matter for body dissatisfaction and disordered eating behaviors in adolescent girls?. 2010. 
Ogden CL, Carroll MD, Curtin LR, Lamb MM, Flegal KM. Prevalence of high body mass index in US children and adolescents. Journal of the American Medical Association. 2010; 303:242-249. [PubMed: 20071470]

Porter J. Relationship among perceptions of teasing, self-esteem, depression, coping strategies and body image among obese adolescents. Dissertation Abstracts International: Section B. Psychotherapy. 2008; 69(5):3316849.

Pulvers KM, Kaur H, Nollen NL, Greiner KA, Befort CA, Hall S..., Ahluwalie JS. Comparison of body perceptions between obese primary care patients and physicians: Implications for practice. Patient Education and Counseling. 2008; 73:73-81. [PubMed: 18583089]

Pulvers KM, Lee RE, Kaur H, Mayo MS, Fitzgibbon ML, Jeffries SK, Ahluwalia JS. Development of a culturally relevant body image instrument among urban African Americans. Obesity Research. 2004; 12:1641-1651. [PubMed: 15536228]

Rasmussen F, Eriksson M, Nordquist T. Bias in height and weight reported by Swedish adolescents and relations to body dissatisfaction: the COMPASS study. European Journal of Clinical Nutrition. 2007; 61:870-876. [PubMed: 17228352]

Rhee KE, De Lago CW, Arscott-Mills T, Mehta SD, Davis RK. Factors associated with parental readiness to make changes for overweight children. Pediatrics. 2005; 116:e94-e101. [PubMed: 15995022]

Rolland K, Farnill D, Griffiths R. Body figure perceptions and eating attitudes amoung Australian schoolchildren aged 8 to 12 years. International Journal of Eating Disorders. 1997; 21:273-278. [PubMed: 9097200]

Roy M, Gauvin L. Casting weight goal as a function of weight status among a representative population-based sample of adolescents. Body Image. 2009; 6:277-284. [PubMed: 19560411]

Sands R. Reconceptualization of body image and drive for thinness. International Journal of Eating Disorders. 1999; 28:397-407. [PubMed: 11054786]

Schwimmer JB, Burwinkle TM, Varni JW. Health-related quality of life of severely obese children and adolescents. Journal of the American Medical Association. 2003; 289:1813-1819. [PubMed: 12684360]

Shaw H, Ramirez L, Trost A, Randall P, Stice E. Body image and eating disturbances across ethnic groups: more similarities than differences. Psychology of Addictive Behaviors. 2004; 18:12-18. [PubMed: 15008681]

Shunk JA, Birch LL. Girls at risk for overweight at age 5 are at risk for dietary restraint, disinhibited overeating, weight concerns, and greater weight gain from 5 to 9 years. Journal of the American Dietetic Association. 2004; 104:1120-1126. [PubMed: 15215771]

Skelton JA, Busey SL, Havens PL. Weight and health status of inner city African American children: Perceptions of children and their parents. Body Image. 2006; 3:289-293. [PubMed: 18089231]

Stern M, Mazzeo SE, Gerke CK, Porter JS, Bean MK, Laver JH. Gender, ethnicity, psychosocial factors, and quality of life among severely overweight, treatment-seeking adolescents. Journal of Pediatric Psychology. 2007; 32:90-94. [PubMed: 16818482]

Stice E, Shaw HE. Role of body dissatisfaction in the onset and maintenance of eating pathology: a synthesis of research findings. Journal of Psychosomatic Research. 2002; 53:985-993. [PubMed: 12445588]

Teixeira PJ, Going SB, Houtkooper LB, Cussler EC, Metcalfe LL, Blew RM, Lohman TG. Pretreatment predictors of attrition and successful weight management in women. International Journal of Obesity and Related Metabolic Disorders. 2004; 28:1124-1133. [PubMed: 15263921]

Thompson SH, Corwin SJ, Sargent RG. Ideal body size beliefs and weight concerns of fourth-grade children. International Journal of Eating Disorders. 1997; 21:279-284. [PubMed: 9097201]

Truby H, Paxton SJ. The Children's Body Image Scale: Reliablity and use with international standards for body mass index. The British Journal of Clinical Psychology. 2008; 47:119-124. [PubMed: 17971282]

Wallander JL, Taylor WC, Grunbaum JA, Franklin FA, Harrison GG, Kelder SH, Schuster MA. Weight status, quality of life, and self-concept in African American, Hispanic, and white fifthgrade children. Obesity. 2009; 17:1363-1368. [PubMed: 19197260] 
Wang Y, Liang H, Chen X. Measured body mass index, body weight perception, dissatisfaction and control practices in urban, low-income African American adolescents. BMC Public Health. 2009:9. [PubMed: 19134207]

Welch C, Gross SM, Bronner Y, Dewberry-Moore N, Paige DM. Discrepencies in body image perception among fourth-grade public school children from urban, suburban, and rural Maryland. Journal of the American Dietetic Association. 2004; 104:1080-1085. [PubMed: 15215765]

Young-Hyman D, Schlundt DG, Herman-Wenderoth L, Bozylinski K. Obesity, appearance, and psychosocial adaptation in young African American children. Journal of Pediatric Psychology. 2003; 28:463-472. [PubMed: 12968038]

Young-Hyman D, Tanofsky-Kraff M, Yanovski SZ, Keil M, Cohen ML, Peyrot M, Yanovski JA. Psychological status and weight-related distress in overweight or at-risk-for-overweight children. Obesity. 2006; 14:2249-2258. [PubMed: 17189553]

Zeller MH, Ingerski LM, Wilson L, Modi A. Factors contributing to weight misperception in obese children presenting for intervention. Clinical Pediatrics. 2010; 49:330-336. [PubMed: 20075030] 


\section{Highlights}

- Black and White overweight girls enrolled in a pediatric obesity intervention experienced comparable levels of body dissatisfaction, despite variations in body size ideals.

- All but one girl desired a body size smaller than their current one, indicating pervasive body dissatisfaction.

- Significant weight misperceptions were also evident.

- Research evaluating the impact of body dissatisfaction, body ideals, and body size perceptions on pediatric obesity intervention efforts are needed.

- Greater attention to eating disorder risk factors among racially-diverse, overweight, treatment-seeking youth is also recommended. 


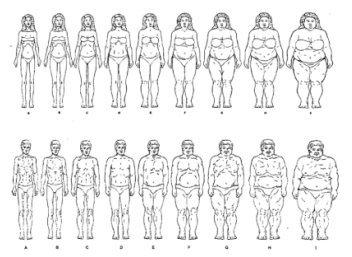

Figure 1. Culturally Relevant Figure Rating Scale Figures from Pulver et al.'s (2004) culturally relevant measure of body dissatisfaction. These figures were reproduced with the written permission of their creators. 


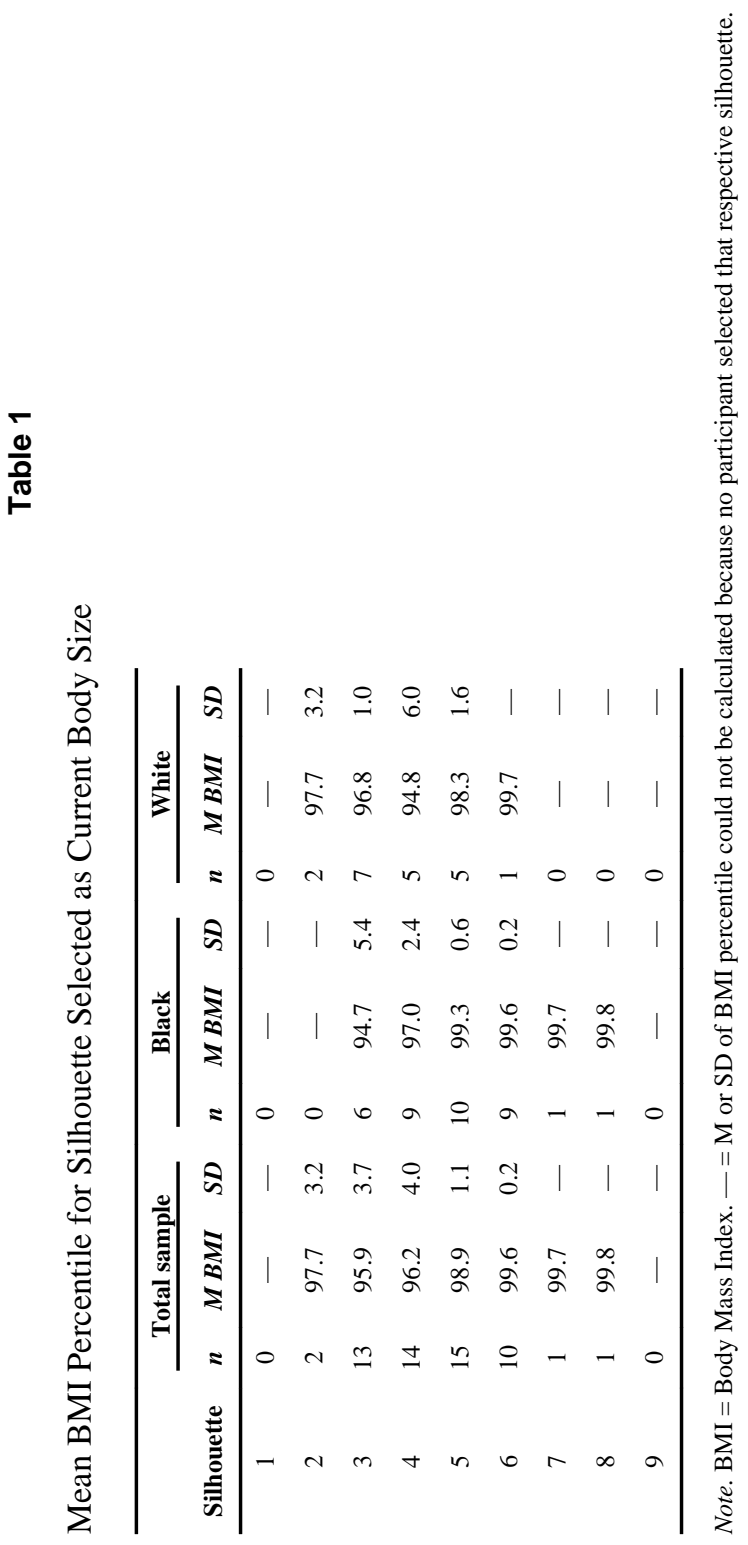

Body Image. Author manuscript; available in PMC 2012 September 1. 